\title{
Farenheit 451: relações entre o leitor de histórias em quadrinhos com cenários distópicos
}

\author{
André Roberto Custódio Neves ${ }^{1}$ \\ Andréa Pereira dos Santos ${ }^{2}$
}

\begin{abstract}
Resumo
Relações entre o livro best-seller Farenheit 451, (Ray Bradbury, 1953), adaptado para o formato em quadrinhos e o leitor. Sua narrativa distópica delineia questões relevantes, como injustiças sociais, política e manipulação da mídia, enquanto metáforas que possam ressignificar o papel sociocultural dos indivíduos. Quadrinhos são recursos que contribuem para formação do pensamento humanizado, devido sua narratividade ser formada pela junção de imagens e textos. Este artigo propõe uma pesquisa descritiva por meio de referenciais bibliográficos e levantamento de dados, demonstrando possibilidades de introjeção de conhecimento através de uma leitura crítica.
\end{abstract}

\section{Palavras-chaves}

Sujeito e Leitura. Quadrinhos. Distopia.

\begin{abstract}
Relations between the best-selling book Farenheit 451, (Ray Bradbury, 1953), adapted for the comic book format and the reader. His dystopian narrative outlines relevant issues, such as social injustices, politics, and media manipulation, as metaphors that can resignify the sociocultural role of individuals. Comics are resources that contribute to the formation of humanized thinking, because their narrativity is formed by the junction of images and texts. This article proposes a descriptive research through bibliographic references and data collection, demonstrating the possibility of knowledge introjection through a critical reading.
\end{abstract}

\section{Keywords}

Subject and Reading. Comics. Dystopia.

\footnotetext{
1 Mestrando em Mídia e Cultura do Programa de Pós-Graduação em Comunicação - PPGCom, da Faculdade de Informação e Comunicação - FIC/UFG brasuka10@gmail.com 2 Doutora em Geografia pela Universidade Federal de Goiás. Mestre em Comunicação pela Universidade Federal de Goiás. andreabiblio@gmail.com
} 


\section{A ficção científica entre textos e imagens}

Este artigo propõe uma relação entre o real e o imaginário presentes nas histórias em quadrinhos, sobretudo, na obra best-seller Farenheit 451 (BRADBURY, 1953) - adaptada para o formato em quadrinhos - pelo viés sociocultural. Nesse sentido, busca por uma percepção mais ativa do contexto social contemporâneo relacionado à distopia, categoria voltada para o campo da ficção científica especulativa ${ }^{3}$ com características que afetam tanto passado quanto presente da sociedade e suas relações com leitor.

Abordando temas relevantes como injustiças sociais, política e manipulação da mídia, dentre outros, Farenheit 451 desempenha um papel importante para a sociedade através de uma rica leitura formada por textos e imagens que garantem a apropriação das mensagens e promovem a construção e desenvolvimento do pensamento crítico.

Por meio destas considerações, o presente artigo visa analisar através de uma pesquisa descritiva e bibliográfica, a capacidade dos quadrinhos em informar e provocar sentimentos nos indivíduos, em sua relação com o mundo real por meio da produção, reprodução e circulação de sentidos, veiculação e transmissão de valores sociais necessários para a construção de uma sociedade empoderada e consciente.

Para Eisner, os quadrinhos transmitem conceitos, ideologias e sistemas que tangem as esferas sociais e políticas. Segundo o autor:

Os quadrinhos procuraram tratar de assuntos que até então haviam sido considerados como território exclusivo da literatura, do teatro ou do cinema. Autobiografias, protestos sociais, relacionamentos humanos e fatos históricos foram alguns dos temas que passaram a ser abraçados pelas histórias em quadrinhos. As graphic novels com os chamados 'temas adultos' proliferaram e a idade média dos leitores aumentou, fazendo com que o mercado interessado em inovações e temas adultos se expandisse (EISNER, 2013, p. 08).

\footnotetext{
3 O termo ficção especulativa tem três significados historicamente localizados: um subgênero de ficção científica que lida com problemas humanos e não tecnológicos, um gênero distinto e oposto à ficção científica em seu foco exclusivo em futuros possíveis e uma super categoria para todos os gêneros que, deliberadamente, se afastam da imitação da realidade de consenso da experiência cotidiana. Nesse último sentido, a ficção especulativa inclui fantasia, ficção científica e horror, mas também seus derivados, híbridos e gêneros cognatos como gótico, distopia, ficção estranha, ficção pós-apocalíptica, histórias de fantasmas, histórias de super-heróis, história alternativa, steampunk, slipstream, realismo mágico, contos de fadas fraturados e muito mais. 0 entendimento da ficção especulativa surgiu em resposta à necessidade de um termo geral para uma ampla gama de formas narrativas que subvertem a mentalidade pós-lluminismo: uma que há muito excluía das histórias da literatura que se afastavam da realidade de consenso ou abraçavam uma versão diferente da realidade que a empírica-materialista. Situada contra as reivindicações desse paradigma, a ficção especulativa surge como uma ferramenta para desmantelar o viés cultural ocidental tradicional em favor da literatura que imita a realidade.
} 


\section{VOZES $_{\text {\&DÁLORO }}^{\mid}$}

Itajaí, v. 18, n. 02, jul/dez 2019

Assim, as histórias em quadrinhos apresentam uma forma lúdica e prazerosa de leitura, além de ser um meio de comunicação de massa que agrega dois códigos (linguístico e pictórico) na transmissão de mensagens que inferem na produção de sentidos nos leitores. Para McCloud (2005, p. 20), as narrativas sequenciais são "imagens pictóricas e outras justapostas em sequência deliberada destinadas a transmitir informações e/ou produzir uma resposta no espectador." Ou seja, elas contribuem para a aquisição de conhecimento, pois seus recursos informacionais e comunicativos são significantes para o contexto sociocultural dos indivíduos.

As contribuições intelectuais despertadas no leitor, por meio da narrativa em quadrinhos de Farenheit 451 são sentidas através da emissão de informações presentes nos textos e ilustrações da graphic novel - portanto, um meio de compreensão do mundo real através do imaginário, suas metáforas e analogias. É necessário frisar, aliás, que o gênero distópico não é novo, pois o tema pode ser encontrado em outros meios de comunicação - romances, filmes, séries e games - que partem do questionamento da vida social e suas formas de alienação cultural que dominam as massas e opõem-se a capacidade crítica da sociedade.

Figura 01: Capa da graphic novel Farenheit 451 (2011)

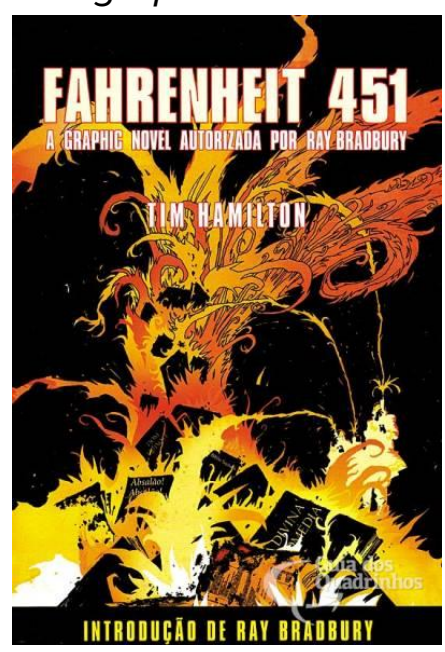

Fonte: http://guiadosquadrinhos.com/edicao/fahrenheit-451/fa005103/91385

\footnotetext{
${ }^{4} \mathrm{~A}$ definição de graphic novel foi popularizada por Will Eisner depois de aparecer na capa de sua obra A ContractwithGod (Um Contrato com Deus) publicada em 1978, um trabalho maduro e complexo, focado na vida de pessoas ordinárias no mundo real. O selo de "graphic novel" foi colocado na intenção de distingui-lo do formato de quadrinhos tradicional. Eisner citou como inspiração os livros de Lynd Ward, que produzia romances completos em xilogravura. O sucesso comercial de Um Contrato com Deus ajudou a estabilizar o termo graphic novel. Fonte: https://www.conhecimentogeral.inf.br/graphic_novel/
} 


\section{VOZES $_{\text {\&IÁLORO }}^{\mid}$}

Itajaí, v. 18, n. 02, jul/dez 2019

Assim, as relações entre contexto da leitura desta obra em quadrinhos e o sujeito leitor remete à verdadeira necessidade de discutir e avaliar as situações que a sociedade enfrenta diariamente, interferindo no desenvolvimento intelectual destes atores sociais.

\section{O real e imaginário em Farenheit 451}

Ao analisar as histórias em quadrinhos pelas lentes do real e imaginário, acreditase que as metáforas ecoam na mente e na alma dos leitores, levando-os a buscar suas próprias reflexões pessoais. É possível que o imaginário desperte nos indivíduos - ou como preferir, atores sociais - uma catarse, um estado de libertação da mente onde a cultura constitui-se no epicentro desta transformação de pensamento.

A isto, Durand (1984) percebe que os elementos que formam o imaginário possuem uma função reprodutiva de símbolos, imagens, mitos e arquétipos formadores da cultura humana, cujo principal atributo é elevar o grau de consciência do homem por meio de extensivo estudo e produção cultural.

$\mathrm{O}$ autor afirma que:

Pela arquetipologia, pela mitologia, pela estilística, pela retórica e pelas belas-artes, sistematicamente ensinadas, poderiam ser restaurados os estudos literários e reequilibrada a consciência do homem de amanhã. Um humanismo planetário não se pode fundar sobre a exclusiva conquista da ciência, mas sobre o consentimento e a comunhão arquetipal das almas. Assim, a antropologia permite [...] que a vocação ontológica manifestada pela imaginação e suas obras parece constituir o coração (DURAND, 1984, p. 498).

Especialmente, quando oriundas dos meios de comunicação - cinema, séries, literatura, games e, neste caso específico, os quadrinhos - pois delineia um trajeto antropológico do imaginário, no sentido de conferir desenvolvimento intelectual nos indivíduos, despertando-os das cadeias alienantes do sistema vigente. A imaginação, a geração de sentidos como processo de simbolização e introjeção de conhecimento desaliena os sujeitos que, entrando em contato com os objetos que o divertem, incorrem na construção e desenvolvimento sociocultural. A ideia, enfim, de que o imaginário "tornase conhecimento de um domínio real, e este conhecimento de um 'sobre-naturalismo' é por si mesmo revelação” (DURAND, 1969, p. 20).

Escrito em1953, Farenheit 451 apresentou tensões que logo seriam sentidas pela sociedade, pois relata a narrativa de uma nação que encontra-se alienada do seu estado de conhecimento e que serve aos propósitos da indústria cultural e instituições heterônomas de poder. Para Bradbury (2012): 


\section{VOZES $_{\text {\&IÁLOGO }}^{\mid}$}

Itajaí, v. 18, n. 02, jul/dez 2019

O esclarecimento, ou seja, a razão instrumental, é a radicalização da angústia mítica, escreveram Adorno e Horkheimer - e a imaginação literária do século XX foi pródiga em criar sociedades fictícias em que a racionalidade se transforma num fim em si mesma: abstrata, mecanicista, reduzindo o existente a um utensílio, alienando a consciência na linha de montagem e produzindo massacres com planejamento industrial (BRADBURY, 2012, p. 14).

Encontramos no contexto da obra, uma sociedade acrítica, monitorada por um regime totalitário que oprime o cidadão comum e tolhe seus direitos básicos; um mundo onde a escrita foi perdendo espaço para a diversão efêmera e alienante de certos meios de comunicação (neste caso, retratado pela televisão), tornando o ser humano em algo meramente instrumental e sem alma. Para Bradbury (2012, p. 17) "nenhum leitor de romance terá dificuldade em ver nesse quadro desolador um instantâneo de nossa realidade mais cotidiana”, com indivíduos cada vez mais torpes, envolvidos em seus mundos individuais, particularizados e regados por entretenimentos passageiros que não contribuem adequadamente para conhecimento.

Em Farenheit 451, aos poucos, os indivíduos foram abandonando o desenvolvimento sociocultural para se concentrarem em programações vazias de sentido e existência, através de produções culturais que, controladas por um tipo de poder institucionalizado e totalizante, determina as condições de vida do indivíduo sujeitado, permeando seus gostos e desejos através de objetos de consumo.

A indústria cultural, portanto, objetiva repelir o indivíduo de sua criticidade, deformando os detalhes que promovem seu raciocínio crítico.

Conforme as palavras de Crocco:

A regressão das consciências promovida pela indústria cultural vai além da neutralização do potencial artístico e cultural. A técnica subjugada à função da economia no capitalismo tardio tem a função de lograr as consciências dos indivíduos. A indústria cultural está associada à análise do totalitarismo, da idéia de uma sociedade totalmente administrada, a qual está associada diretamente com o advento da sociedade de massas e da sociedade de consumo. Para Adorno e Horkheimer, a indústria cultural ao despejar os bens culturais industrializados no mercado induz as massas ao consentimento do capitalismo. $\mathrm{O}$ interesse ideológico de transformar o público em massa consumidora pela simples distração é o mesmo das classes dominantes em perpetuar seus interesses econômicos e políticos (CROCCO 2009, p. 06). 


\section{VOZES $_{\text {\&DÁLORO }}^{\mid}$}

Itajaí, v. 18, n. 02, jul/dez 2019

As histórias em quadrinhos, sobretudo, a adaptação do texto de Bradbury para a nona $\operatorname{arte}^{5}$ e enquanto artefato cultural desperta interesse do público leitor. Afinal, este tipo de leitura tende a dar vazão a conceitos e ideias contemporâneas ao gerar sentidos e até mesmo possibilitar o rompimento com paradigmas estanques e valores socioculturais instrumentalizados. Tal evidência demonstra que histórias oriundas da literatura de massa podem até ser ficcionais ou imaginárias, porém, embasadas em situações e eventos aparentemente similares ao mundo real, com suas referências nas várias esferas da sociedade.

Para Sodré:

[...] o que importa mesmo são os conteúdos fabulativos (e, portanto, a intriga com sua estrutura clássica de princípio-tensão, clímax, desfecho e catarse), destinados a mobilizar a consciência do leitor, exasperando a sua sensibilidade (SODRÉ, 1988, p. 16).

E mais:

O texto de massa mantém visível a sua estrutura através de personagens fortemente caracterizados, de uma abundância de diálogos (capazes de permitir uma adesão mais intensa do leitor à trama) e de uma exploração sistemática da curiosidade do público (SODRÉ, 1988, p. 17).

Atribuindo significados para a compreensão dos sentidos, a imaginação pode aproximar-se do real, possibilitando discernir daquilo que ainda não se tornou fato. A existência das coisas e dos homens faz entender que a realidade já é algo dado, basta ser percebida e interpretada. E o imaginário possui um compromisso com a realidade, naquilo

\footnotetext{
${ }^{5}$ No começo eram as artes, como a dança, escultura, literatura, música, pintura e teatro. E as artes eram boas e todas eram iguais aos olhos dos criadores. As artes existiam e faziam com que os apreciadores se sentissem um pouco mais humanos e com que os criadores se sentissem plenos. Mas o homem, em sua infinita insatisfação e busca por expressão, inventou o cinema. E o cinema maravilhou apreciadores e encantou criadores. E Ricciotto Canudo o considerou a mais completa das artes, pois englobava todas as outras artes. E em 1923 publicou o "Manifesto das Sete artes" organizando-as da seguinte forma: $1^{\mathrm{a}}$ Arte - Música (som); $2^{\mathrm{a}}$ Arte -

Dança/Coreografia (movimento); $3^{a}$ Arte - Pintura (cor); $4^{a}$ Arte - Escultura (volume); $5^{a}$ Arte Teatro (representação); $6^{a}$ Arte - Literatura (palavra); $7^{a}$ Arte - Cinema (integra os elementos das artes anteriores). A partir daí as artes passaram a ter classificação e a serem vistas tanto por apreciadores quanto por criadores com olhos cartesianos. E quando Canudo chegou à clareira no final da estrada, outros homens continuaram seu trabalho de sistematização das artes: $8^{a}$ Arte - Fotografia (imagem); $9^{a}$ Arte - Quadrinhos (cor, palavra, imagem); $10^{a}$ Arte - Jogos de Computador e de Vídeo (no mínimo integra as $1^{\mathrm{a}}, 3^{\mathrm{a}}, 4^{\mathrm{a}}, 6^{\mathrm{a}}, 9^{\mathrm{a}}$ arte); $11^{\mathrm{a}}$ Arte - Arte digital (integra artes gráficas computorizadas 2D, 3D e programação). Os quadrinhos, que começaram como entretenimento simples, barato e de massa, evoluíram e se estabeleceram definitivamente como arte. E como arte se apresentam ao mundo, como a nona arte. Fonte: http://quadro-aquadro.blog.br/por-que-quadrinho-e-a-nona-arte/
} 


\section{VOZES $_{\text {\&IÁLORO }}^{\mid}$}

Itajaí, v. 18, n. 02, jul/dez 2019

que pode ser percebido por meio de sinais ou signos de referência - a imagem constituída por representações.

Maffesoli afirma que:

[...] o imaginário, mesmo que seja difícil definí-lo, apresenta, claro, um elemento racional, ou razoável, mas também outros parâmetros, como o onírico, o lúdico, a fantasia, o imaginativo, o afetivo, o não racional, o irracional, os sonhos, enfim, as construções mentais potencializadoras das chamadas práticas. De algum modo, o homem age por que sonha agir. O que chamo de 'emocional' e de 'afetual' são dimensões orgânicas do agir a partir do espírito. Evidentemente que a prática condiciona as construções do espírito, mas estas também influenciam as práticas (MAFFESOLI 2001, p. 76).

Ao que Barros diz:

Maffesoli polemiza: imaginário é a realidade. Como alguém pode afirmar isso? Como o imaginário, produto da imaginação, pode ter a pretensão de ser real? É que, para Maffesoli, imaginário é viver os sonhos mais do que sonhá-los. Isso é uma afronta ao signo, ao significado e ao significante. Imagem, portanto, não é signo. O signo só quer clareza, ao passo que o imaginário tem uma carga semântica ambígua, situando-se entre o palpável e o impalpável, o líquido e o concreto. $\mathrm{O}$ trajeto antropológico se dá quando se constrói uma bacia semântica (metáfora de autoria de Durand) inundada por uma força emocional que também é racionalizadora. O ser humano vive, portanto, uma constante necessidade de equilíbrio, nesta gangorra existencial, entre as imposições do meio e a sua própria subjetividade (BARROS 2013, p. 322).

O imaginário mostra-se, portanto, grande fonte de alegorias e manifestações culturais, fornecendo aos indivíduos novas formas de pensar suas próprias condições na sociedade. Nos quadrinhos, tal condição permite ao leitor passear entre possibilidades variadas de entendimento da relação entre indivíduo e sociedade, real e imaginário, passando por análises e discussões que geram produção de sentidos e transmissão de conhecimentos.

Imagine, portanto, um meio de comunicação como os quadrinhos, que utilizam-se da junção entre texto e imagem para transportar o leitor a um futuro distópico onde os bombeiros não apagam incêndios, mas os provocam - parece um pesadelo.

Nos quadrinhos de Farenheit 451, a leitura da obra permite um alcance interpretativo mais aguçado graças à parceria entre roteiro e ilustração, que ajudam numa melhor aproximação do indivíduo para com a leitura, devido ao olhar que se tem das imagens e da interpretação ressignificada do texto.

Para Eisner: 


\section{VOZES $_{\text {\&IÁLORO }}^{\mid}$}

Itajaí, v. 18, n. 02, jul/dez 2019

Esta é uma forma de arte relacionada ao realismo, porque se propõe a contar histórias. A arte seqüencial lida com imagens reconhecíveis. [...] Na prática, o artista 'imagina' para o leitor. [...] Numa forma de arte em que o escritor/artista deve dominar um amplo repertório de fatos e informações sobre inúmeros temas, a aquisição de conhecimentos é interminável. Afinal, trata-se de uma forma artística que trata da experiência humana (EISNER, 1989, p. 144-145).

São obras como esta que conferem fidelidade e realismo à leitura e seus temas são bem contemporâneos: desigualdades sociais, injustiças, política e religião. Exemplos que podem ser encontrados nas narrativas sequenciais que fomentam o exercício da imaginação.Os quadrinhos - tidos como expressões de arte e cultura - possuem grande apreço pela sociedade, percebidos tanto como entretenimento quanto eficaz ferramenta de cunho educativo e social.

Thompson (1999, p. 20), ao propor a análise sociológica dos meios de comunicação, afirmaque "se a comunicação é uma forma de ação, a análise da comunicação deve se basear, pelo menos em parte, na análise da ação e na consideração do seu caráter socialmente contextualizado.”

Segundo o autor:

A recepção das formas simbólicas - incluindo os produtos da mídia sempre implica um processo contextualizado e criativo de interpretação, no qual os indivíduos se servem dos recursos de que dispõem para dar sentido às mensagens que recebem (THOMPSON, 1999, p. 17).

Sendo assim, todo e qualquer produto midiático é um artefato de comunicação e cultura que flerta com a realidade e até mesmo infere nas possibilidades interpretativas de cada um, possibilitando reflexões significativas através de trocas de experiências entre os sujeitos, viabilizando a identificação e descoberta de seu lugar humanizado no mundo, visualizando a si próprio e o outro nas relações de busca e geração de sentido em suas vidas.

A identificação do público leitor por obras que envolvem o real e o imaginário como fonte de desenvolvimento cultural, como é o caso dos quadrinhos, podem gerar mudanças comportamentais e de valores através da empatia e introjeção de conhecimento, servindo como janelas da realidade que retratam o contexto e os anseios da cada sujeito em sua jornada pessoal por aspirações mais elevadas.

\section{Narrativa distópica}

São várias obras literárias que descrevem universos distópicos, tais como Admirável Mundo Novo (1931), Revolução dos Bichos (1945), 1984 (1949), Laranja Mecânica (1962) 


\title{
VOZES $_{\text {\&IÁLORO }}^{\mid}$
}

Itajaí, v. 18, n. 02, jul/dez 2019

e O Conto de Aia (1985). Nos quadrinhos, há várias narrativas representativas deste cenário: Juíz Dredd (1977), Akira (1982), Incal (1983), V de Vingança (1988), Y - O Último Homem (2003), Lazarus (2013), entre outros. Além de filmes como Metrópolis (1927), Blade Runner (1982), Matrix (1999) e Jogos Vorazes (2012).

A distopia carrega um forte senso crítico ao sistema governamental, seu poder político, social, cultural e até mesmo midiático. Quando tem-se a intenção de manifestar conceitos, ideologias e até mesmo tecer críticas ao governo ou outras instituições, o uso da narrativa distópica como contraponto e protesto é um bom recurso. Sua escolha se dá pela relevância e atualidade de temas tão próximos dos indivíduos, situações que se assemelham ao dia a dia na sociedade e que delineam discussões sobre o futuro das coisas.

Pode-se dizer que a ficção científica é uma boa forma de lidar com temas da atualidade - relações de poder com suas regras e controle das massas, cerceamento da liberdade e individualidade, mídia alienante com programações que oferecem pouco ou nada para a construção social e crítica. À distopia atribui-se contextos narrativos sobre o futuro mas, na verdade, o que se quer falar é a respeito de um passado recente e/ou também presente: cenários político, social e cultural que sofrem grandes retrocessos de caráter econômico, com altas taxas de desempregos e educação precária, por exemplo.

A ficção distópica tem muito onde se espelhar para narrar contextos tão atuais para a sociedade quanto agora, com crises sociais que permeiam o país e o mundo. Para Eco (1994, p. 93) "ler ficção significa jogar um jogo através do qual somos capazes de dar um sentido à imensidão de coisas que aconteceram, estão acontecendo, ou vão acontecer no mundo real.”

Para Dumont, isto significa que:

\begin{abstract}
As implicações do contexto onde se produz uma ação e onde se produz um texto, ou mesmo uma obra de arte, um discurso, uma teoria, enfim, onde e quando qualquer produção ou ação humana se efetiva, devem constituir o primeiro acesso para interpretar e entender qualquer manifestação de um sujeito, ou de uma coletividade (DUMONT, 2001, p. 44).
\end{abstract}

Vários são os quadrinhos que retratam cenários futuros - como é o caso de Farenheit 451 - em que o leitor é transportado para sociedades fictícias e totalitárias, cenários onde os indivíduos se veem diante de uma realidade em que o pensamento é proibido, a leitura enseja perigos para a sociedade, as informações são controladas por instâncias heterônomas e os cidadãos tornam-se uma massa alienada pelos canais de comunicação.

Dominados, são incapazes de formular argumentos e protestos contra o sistema em que estão inseridos, uma prisão sem muros.A narrativa sequencial de Farenheit 451, mesmo sendo fictícia, continua próxima à realidade: universidades colocadas em xeque, Educação precária e insuficiente, homens-livros (ex-professores) vagueiam pelas trilhas e 


\section{VOZES $_{\text {\&IÁLORO }}^{\mid}$}

Itajaí, v. 18, n. 02, jul/dez 2019

estradas desertas com livros de Filosofia e Antropologia guardadas apenas em suas memórias, já que tais edições são proibidas e queimadas pela censura.

A forma como o futuro é retratado faz com que o leitor enxergue como seria um mundo onde o livre pensamento é desestimulado, programas de televisão e outros sem sentido são lançados no intuito de distrair as massas dos problemas reais da sociedade, livros históricos são vistos como artefatos perigosos e levados à extinção, caçados a todo custo pelos bombeiros, o passado é apagado por estratagemas mesquinhos e autoritários numa tentativa de reconfiguração da História, o conhecimento é desestimulado e os jovens perdem interesse nos estudos, priorizando outros fatores como o trabalho e o lazer descompromissado.

Montag, protagonista da obra, é um agente do governo que promove a queima de livros, por serem considerados perniciosos e trazer discussões para a sociedade - trágica ironia, os quadrinhos carregam o fardo de se encaixar no modelo de baixa cultura, como um produto semiformativo e semicultural. Enquanto que, na obra em questão, ocorre o contrário: a literatura culta é perseguida pelo seu teor filosófico.

Neste cenário, um regime totalitário comanda o corpo de bombeiros, sua função é queimar qualquer tipo de literatura impressa. Estes censores da cultura incineram os livros, pois as palavras são proibidas e os livros são caçados, apreendidos e destruídos - inclusive, indivíduos que discordam de tal regime são punidos pelas chamas e queimados juntos com suas bibliotecas. $\mathrm{O}$ contexto da obra tenta formular na mente dos leitores um imaginário repleto de semelhanças com o mundo real, tentando apresentar aos mesmos nuances e camadas da sociedade que, no fim, não são tão diferentes daquilo que uma obra de ficção literária oferece.

Refletir sobre a vida e as experiências que ela oferece são, em Farenheit 451, catalizadores de angústia e tristeza para a alma humana e Montag representa a dualidade da vida sistemática e sem propósito versus a busca por inovação e compreensão do status quo vigente. No decorrer da obra, o protagonista desperta de sua ignorância, percebendo que o mundo ao qual enxergava já não faz mais sentido, pois sua consciência mudou.

Ao passo que Sodré (1988, p. 17) relata que "a função da literatura é criar, partindo do material bruto da existência real, um mundo novo que será mais maravilhoso, mais durável e mais verdadeiro do que o mundo visto pelos olhos do vulgo.”

\section{Considerações finais}

O presente artigo buscou na leitura das histórias em quadrinhos um meio de introjeção de conhecimento através da graphic novel Fahrenheit 451, que representa uma ambientação situada num futuro distópico. Acredita-se que por meio das narrativas sequenciais abre-se um novo campo de descobertas, capaz de oferecer tensões e conflitos 


\section{VOZES: \\ DIÁLOGO}

Itajaí, v. 18, n. 02, jul/dez 2019

narrativos que promovem um despertar de consciência no leitor e faz com o que o mesmo perceba o mundo ao seu redor de outra forma, sugerindo mudanças e quebras de paradigmas imóveis.

A leitura de artefatos culturais como os quadrinhos enseja inúmeras possibilidades de crescimento intelectual, podendo ser vistas não apenas pela ótica do entretenimento, mas, sobretudo, a partir da possibilidade de geração de significantes representações socioculturais, mediante a leitura e interpretação de textos e imagens. Portanto, o desenvolvimento dos meios de comunicação gera produção, reprodução e circulação de sentidos de maneira profunda e irreversível, fomentando a construção e desenvolvimento dos indivíduos na sociedade por meio de exercícios reflexivos.

Bradbury apropriava-se da ficção científica para abordar temas delicados, na tentativa (bem sucedida, aliás) de gerar reflexões inquietantes nos indivíduos e despertá-los de sua inércia, causada pela ação de regimes totalitários e demais instituições. No caso do Brasil, recomenda-se maiores cuidados para com o legado do conhecimento, haja vista que o país tende a se curvar ante a dominação imposta pelas mídias que neutralizam a criticidade e anulam o intelecto, embalado por distrações que visam entorpecer o pensamento crítico. Uma questão paira no ar, ao cheiro de querosene: quão perto se está de uma extinção total da intelectualidade, causada pelo fogo da ignorância?

Ler quadrinhos, assim como estar em contato com outros meios de comunicação que agregam valores socioculturais, tem o poder de ressignificar posturas e atitudes e volta e meia os povos necessitam rever seus próprios conceitos e ideais.

Como dito por Eco:

O universo das comunicações de massa é o nosso universo; e se quisermos falar de valores, as condições objetivas das comunicações de massa são aquelas fornecidas pela existência dos jornais, do rádio, da televisão, da música reproduzível, das novas formas de comunicação visível e auditiva (ECO, 1979, p. 11).

A importância deste estudo destaca-se pela necessidade em analisar e discutir a capacidade de compreensão do leitor em sua interação com os elementos das histórias em quadrinhos, sobretudo as que permitem uma capacidade de interpretação dos conteúdos presentes nos textos e imagens.

\section{Referências}

BARROS, Eduardo Portanova. A sociologia romântica e o imaginário na obra de Michel Maffesoli. Revista Educere et Educare, Universidade do Vale do Rio dos Sinos, Unioeste, Campus de Cascavel, vol. 08, n. 16, p.321-328, jul-dez. 2013.

BARTHES, Roland. A aventura semiológica. São Paulo: Martins Fontes, 2001. 


\section{VOZES $_{\text {\&IÁLOGO }}^{\mid}$}

Itajaí, v. 18, n. 02, jul/dez 2019

CHARTIER, Roger. A aventura do livro: do leitor ao navegador. São Paulo: Ed. UNESP, 1998.

EISNER, Will. Narrativas gráficas. São Paulo: Devir, 2005.

Quadrinhos e arte sequencial. 4. ed. São Paulo: Martins Fontes, 2010.

DUMONT, Lígia Maria Moreira. Contexto, leitura e subjetividade. Revista Transinformação, PUC Campinas. São Paulo, v. 13, n. 01, p. 43-47, jan.jun. 2001

DURAND, Gilbert. L’exploration de l'imaginaire. Circé, v. 1, p. 15-45, 1969.

DURAND, Gilbert. Lesstructures anthropologiques de l'imaginaire.10. éd. Paris: Dunod, 1984 .

ECO, Umberto. Seis passos pelos bosques da ficção. São Paulo: Ed. Companhia das Letras, 1994

Apocalípticos e integrados.São Paulo: Perspectiva, 2011

MCCLOUD, Scott. Desvendando os quadrinhos. São Paulo: M. Books,2005.

OZIEWICS, Marek. Speculative Fiction. Disponível em:<https:/oxfordre.com/literature/view/10.1093/acrefore/9780190201098.001.0001/acr efore-9780190201098-e-78> Acesso em: setembro de 2019.

SILVA, J. M. Entrevista. Revista FAMECOS. Porto Alegre, nº 15, agosto 2001.

SODRÉ, M. Best-Seller: a literatura de mercado. Rio de Janeiro: Ática, 1988.

THOMPSON, John B. A Mídia e a modernidade: Uma teoria social da mídia.Petrópolis/RJ: Vozes, 1999. 